\title{
New Lead Molecules from Ascidian Phallusia Nigra (Savigny, 1816) for Type-2 Diabetes Mellitus Targeting Aldose Reductase: An in Silico Approach
}

\author{
G. Ananthan*, A. Selva Prabhu \\ CAS in Marine Biology, Faculty of Marine Sciences, Annamalai University, Parangipettai-608 502 Tamil Nadu, India \\ *Corresponding Author: casananthan@yahoo.co.in, antonyrajprabhu@gmail.com
}

Copyright (C) 2014Horizon Research Publishing All rights reserved

\begin{abstract}
Diabetes mellitus is one of the major diseases currently affecting millions of people worldwide. There is a renewed interest in the marine natural products. The present study aimed to identify the bioactive constituents by GC-MS analysis from ascidian P. nigra and screen against type 2 diabetes mellitus protein (aldose reductase) using In-silico approach. Docking studies of the identified compounds were carried out using Arguslab docking software. Analysis of the results indicated Pthalic acid as the potent bioactive constituent attributing Type II Diabetes Mellitus (T2DM) activity from ascidian P. nigra and it showed significant activity than the standard, fidarestat.
\end{abstract}

Keywords Docking, Antidiabetic, Arguslab, T2DM, In-Silico, Ascidian, Phallusia Nigra

\section{Introduction}

Diabetes mellitus is a principal cause of morbidity and mortality in human populations (Steppan et al., 2001). It is a syndrome characterized by hyperglycemia, polydipsia and polyuria and causes complications to the eyes, kidneys, and nerves. It is also associated with an increased incidence of cardiovascular disease (Pickup and Williams, 1991). The clinical manifestations and development of diabetes often differ significantly between countries and also between racial groups within a country. Diabetes mellitus is becoming increasingly common in India, which can be attributed to many factors, including a stressful lifestyle as well as improper dietary habits. This is of economic concern as the disease requires life-long treatment and is also associated with high morbidity from the resulting complications.

Molecular docking is the technique employed for predicting and analyzing the interactions between protein receptors and ligands. It also provides most detailed possible view of drug receptor interactions and also has created a new rational approach to drug design (Bothara, et al, 1998). Diabetes, the third leading cause of death in the world, has many treatment regimens including insulin injections and oral hypoglycemic drugs (Satyavati, et.al, 1989). Inspite of these treatment measures, most diabetic patients eventually experience long term type 2 diabetes mellitus complications, such as retinopathy, neuropathy, cataract and angiopathy. Although there is still no definite pathogenic link between hyperglycemia and diabetic complications, several mechanisms seems to be involved in the toxic effects caused by excess glucose. Among well examined factors, the activation of polyol pathway was first implicated in the etiology of secondary complications of diabetes. Aldose reductase is the first enzyme in the pathway (Nigishi, 1997).

Rational drug design (RDD) helps to facilitate and speedup the drug designing process, which involves variety of methods to identify novel compounds. One such method is the docking of the drug molecule with the receptor (target). The site of drug action, which is ultimately responsible for the pharmaceutical effect, is a receptor and docking is the process by which two molecules fit together in 3D space.

Ascidians are marine invertebrates which ranks second with promising source of drugs (Azumi et al., 1990). Most of the ascidians are utilized as such as food in various countries and they are known to produce bioactive metabolites which prevent bio-fouling and this can be considered as a kind of autogenic protection (Bergquist et al., 1978). This mechanism has proved to be timely alternative natural medicine to human beings. From tunicate (ascidians) Trididemnum solidum, the first marine compound entered human cancer clinical trial as a purified natural product (Carte, 1996), but was unsuccessful in further trials (Davidson, 1993). Already various ascidians such as Botryllus sp., Didemnum sp. were proved for producing anti cancer drugs (Azumi et al., 1990). Halocyamine A, an antimicrobial substance was isolated from haemocytes of the solitary ascidians Halocynthia roretzi (Azumi et al., 1990). The bioactive substance which possesses potent anticancer activity Ecteinascidin-743 was 
isolated from Caribbean Sea squirt Ecteinascidia turbinate (Russo et al., 2008). Such potential Ascidians need to be explored for the pharmaceutical purpose.

The aim of the present study is to investigate the inhibitory activity of the compound, Pthalic acid on type 2 diabetes by molecular docking studies and to analyze the ADME/T properties of the compound for drug like candidates by using the docking software and hence it would serve as to design drug alternative to diabetes. Aldose reductase inhibitors can play a significant role in preventing diabetic complications. The discovery of 3D structure of aldose reductase helped to conduct molecular modeling techniques and thus will be useful for insight into the structure of enzyme bound inhibitor (Shuichi, 2002). As traditional knowledge will serve as a powerful search engine and most importantly, will greatly facilitate intentional, focused and safe natural products research. Hence, an effort was made to screen the traditionally used ascidian, Phallusia nigra for its T2DM activity using docking software, Argus Lab against the receptor protein Aldose Reductase.

\section{Materials and Method}

\subsection{Sample Collection}

Ascidians were collected from Tuticorin coast, Southeast coast of India. The methanol extract of P.nigra was prepared by cold maceration process and subjected for Gas Chromatographic Mass Studies (GCMS) for identifying the constituents present.

\subsection{Molecular Docking}

The 3D structure of Aldose Reductase with the resolution of $0.92 \AA$ was retrieved from the Protein Data Bank (PDB ID: 1PWM) (www.rcsb.org/pdb) and used as target receptor protein. The chemical structure of natural inhibitor (fidarestat) and compounds identified by GCMS method were drawn from SMILES notation (Simplified Molecular Input Line Entry Specification) by using the Chemsketch Software (www.acdlabs.com). Docking analyses was carried out using Argus Lab 4.0.1 software to explore the protein ligand interactions. Docking was performed by selecting "GADock" as the docking engine and Grid resolution was set to $0.40 \mathrm{~A}^{\circ}$. Rest of the settings was left as default. The docked structure was saved as ".pdb" file and binding affinity and molecular interaction between test compounds and the receptor protein were predicted using PyMol Molecular Graphic System (Ver. 1.0) Discovery Studio (Ver 3.1) software, respectively. The energy grid was built within a cubic box and docking was performed based on Lamarckian genetic algorithm (Morris and Goodsell, 1998).

Table 1. Constituents identified in P.nigra methanol extract using GCMS

\begin{tabular}{|c|c|c|c|c|c|}
\hline No. & RT & Name of the Compound & $\begin{array}{c}\text { Molecular } \\
\text { Formula }\end{array}$ & MW & $\begin{array}{l}\text { Peak } \\
\text { Area } \\
\end{array}$ \\
\hline 1 & 3.305 & Dimethyl Sulfoxide & $\mathrm{C}_{2} \mathrm{H}_{6} \mathrm{OS}$ & 78.133 & 23.55 \\
\hline 2 & 3.769 & Oxime-, methoxy-phenyl- & $\mathrm{C}_{8} \mathrm{H}_{9} \mathrm{NO}_{2}$ & 151.162 & 3.89 \\
\hline 3 & 7.110 & Methanesulfonamide, N,N-dimethyl- & $\mathrm{C}_{3} \mathrm{H}_{9} \mathrm{NO}_{2} \mathrm{~S}$ & 123.17 & 1.62 \\
\hline 4 & 8.823 & Tricyclo[4.3.1.1(3,8)]undecan-1-amine & $\mathrm{C}_{11} \mathrm{H}_{19} \mathrm{~N}$ & 165.275 & 5.53 \\
\hline 5 & 9.274 & 2H-Pyrazole, 3-amino-2-isopropyl- & $\mathrm{C}_{6} \mathrm{H}_{11} \mathrm{~N}_{3}$ & 125.171 & 10.50 \\
\hline 6 & 11.452 & Benzenemethanol, .alpha.-[(methylamino)methyl] & $\mathrm{C}_{9} \mathrm{H}_{13} \mathrm{NO}$ & 151.21 & 6.17 \\
\hline 7 & 11.583 & N-Methyl-N-[2-cyanoethyl]-2-mercapto propyl amine & $\mathrm{C}_{7} \mathrm{H}_{14} \mathrm{~N}_{2} \mathrm{~S}$ & 158.264 & 2.19 \\
\hline 8 & 12.759 & Bis(dimethylamido)fluorothiophosphate & $\mathrm{C}_{4} \mathrm{H}_{12} \mathrm{FN}_{2} \mathrm{PS}$ & 170.188 & 5.18 \\
\hline 9 & 12.977 & Propanenitrile, 3-amino-2,3-di(hydroxymino)- & $\mathrm{C}_{3} \mathrm{H}_{4} \mathrm{~N}_{4} \mathrm{O}_{2}$ & 128.089 & 6.58 \\
\hline 10 & 13.137 & 4-Hydroxy-6-(methylamino)pyrimidin & $\mathrm{C}_{5} \mathrm{H}_{7} \mathrm{~N}_{3} \mathrm{O}$ & 125.13 & 8.13 \\
\hline 11 & 13.427 & Acetamide, N-(4-aminophenyl)- & $\mathrm{C}_{8} \mathrm{H}_{10} \mathrm{~N}_{2} \mathrm{O}$ & 150.177 & 4.06 \\
\hline 12 & 13.573 & $\mathrm{~N}$-cyclohexyl-3,4-methylenedioxyamphetamine & $\mathrm{C}_{10} \mathrm{H}_{13} \mathrm{NO}_{2}$ & 179.22 & 3.42 \\
\hline 13 & 13.674 & Pyrimidine-4,6-diol, 5-methyl- & $\mathrm{C}_{5} \mathrm{H}_{6} \mathrm{~N}_{2} \mathrm{O}_{2}$ & 126.113 & 3.57 \\
\hline 14 & 13.761 & 4,5-Diamino-6-hydroxypyrimidine & $\mathrm{C}_{8} \mathrm{H}_{12} \mathrm{~N}_{8} \mathrm{O}_{2} \cdot \mathrm{H}_{2} \mathrm{SO}_{4}$ & 350.31 & 2.18 \\
\hline 15 & 14.691 & 3-Acetamido-5-acetylfuran & $\mathrm{C}_{8} \mathrm{H}_{9} \mathrm{NO}_{3}$ & 167.161 & 2.87 \\
\hline 16 & 14.778 & 2-(5-Aminohexyl)furan & $\mathrm{C}_{10} \mathrm{H}_{17} \mathrm{NO}$ & 167.248 & 6.58 \\
\hline 17 & 17.116 & 3-Piperidinol & $\mathrm{C}_{6} \mathrm{H}_{13} \mathrm{NO}$ & 115.17 & 1.75 \\
\hline 18 & 18.162 & Phthalic acid, butyl 5-methoxy-3-m ethyl pentyl ester & $\mathrm{C}_{13} \mathrm{H}_{11} \mathrm{~F}_{5} \mathrm{O}_{4}$ & 326.216 & 2.24 \\
\hline
\end{tabular}


Table 2. Molecular docking score of the ligand and standard drugs against the receptor protein

\begin{tabular}{|c|c|}
\hline COMPOUND & $\operatorname{SCORE}(\mathrm{kj} / \mathrm{mol})$ \\
\hline Fidarestat & -9.1104 \\
\hline Pthalic acid & -10.5567 \\
\hline Oxime-methoxy-phenyl & -8.9279 \\
\hline Tricyclo & -8.4948 \\
\hline 3-Propoxyamphetamine & -8.2779 \\
\hline Oxime-, methoxy-phenyl & -8.1535 \\
\hline 3-Acetamido-5-acetylfuran & -8.0306 \\
\hline 4-aminoacetanilide & -7.7804 \\
\hline 6-(furan-2-yl)hexan-2-amine & -7.6340 \\
\hline N(4)-methylcytosine & -6.7845 \\
\hline Histidine, 1, N-dimethyl-4-nitro & -6.6741 \\
\hline 1-methylpyridin-1-ium-3-thiol & -6.5592 \\
\hline Pterine-6-carboxylic acid & -6.4775 \\
\hline 3-Hydroxypiperidine & -6.3039 \\
\hline 4-Methyl-1,3-oxazole-5-carboxamide & -6.0207 \\
\hline Dimethyl Sulfoxide & -6.010 \\
\hline 4,5-diaminohypoxanthine & -5.8096 \\
\hline Isoxazol-5-amine & -5.6224 \\
\hline Melamine & -5.1876 \\
\hline Thiono-dimefox & -5.0060 \\
\hline
\end{tabular}

\section{Results and Discussions}

The constituents of methanol extract of P.nigra were analyzed by Gas Chromatographic Mass Spectral studies. All the 18 identified compounds were subjected to docking studies against aldose reductase and compared with standard, fidarestat. The energy values obtained against the receptor using arguslab is tabulated in Table: 2 . The binding energy between plant constituents and aldose reductase ranged from -5.94 to $-10.08 \mathrm{~K} \mathrm{cal} / \mathrm{mol}$. The binding energy of fidarestat against aldose reductase was found to be $-9.62 \mathrm{~K} \mathrm{cal} / \mathrm{mol}$

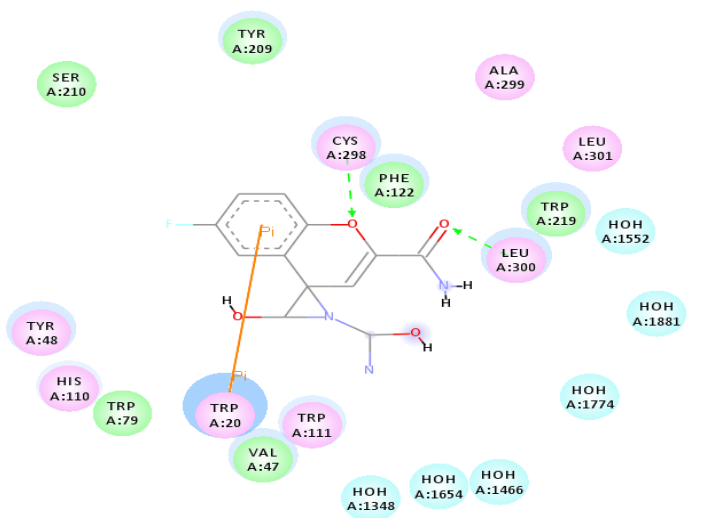

Figure 1. 2D molecular interaction between the standard drug fiderest and the target receptor protein Aldose reductase
The results clearly indicated that Pthalic acid has got maximum activity even greater than the standard compound whereas all other identified constituents also supported its aldose reductase inhibition activity. The interaction of Pthalic acid with aldose reductase is depicted in Figure 1, 2 and 3.

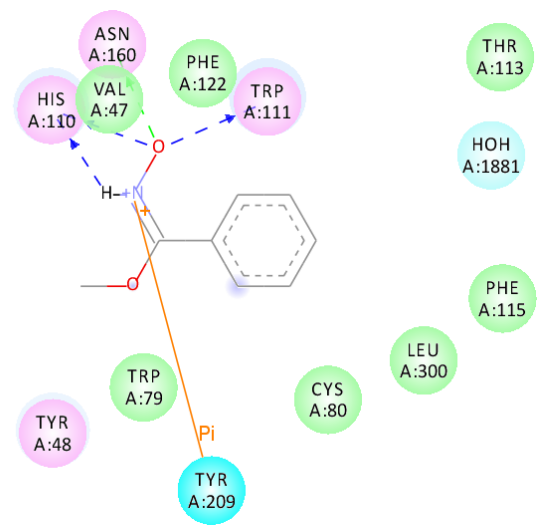

Figure 2. 2D molecular interaction between Oxine methoxy phenyl and the target receptor protein Aldose reductase

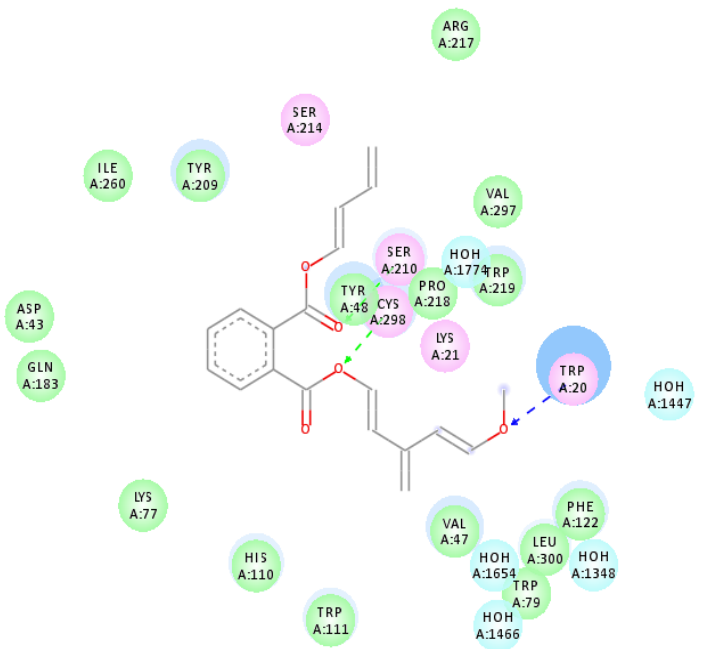

Figure 3. 2D molecular interaction between Pthalic acid and the target receptor protein Aldose reductase

\section{Conclusions}

The field of molecular docking has emerged during last three decades and now is becoming the integral part in drug discovery and development area. The present study helped to identify the potent bioactive constituent present in the methanol extract of P.nigra, attributing aldose reductase inhibitory activity, as Pthalic acid among all other constituents. This result clearly demonstrates that the approach used in the study is successful in finding novel anti-diabetic compounds from ascidians. Also, the study states and confirms the importance of small molecules from ascidians, their use in enhancing protein-ligand interaction studies, In- silico and provide vital clues that can be used to design new molecules with improved activity(S. 
function. J Comput Chem 1998; 19: 1639-62.

[9] Nigishi H (1997) New concepts and insights on pathogenesis and treatment of diabetic complications: polyol pathway and its inhibition. Nagoya J Med Sci. 60: 89-100.

\section{REFERENCES}

[1] Azumi K, Yoshimizu M, Suzuki S, Ezura Y, Yokosawa H (1990) Inhibitory effect of halocyamine, an antimicrobial substance from ascidian hemocytes, on the growth of fish viruses and marine bacteria Cell. Mol. Life Sci., 46(10):1066-1068.

[2] Bergquist PR, Bedford JJ (1978) The incidence of antibacterial activity in marine demospongiae; Systematic and geographic considerations. Marine Biol. 46 (3), 215-221.

[3] Bikadi Z, Hazai E (2009) Application of the PM6 semi-empirical method to modeling proteins enhances docking accuracy of AutoDock. J. Cheminform. 11: 1-15.

[4] Bothara KG, Patil AU, Sexena A (1998) Importance of docking studies in drug design. Indian J Pharm Sci. 60(6): 333-37.

[5] Carte BK (1996) Biomedical potential of marine natural products. Bioscience. 46: 271-286.

[6] Davidson BS (1993) Ascidians producter of amino acid derived metabolites, Chem. Rev. 93: 1771- 1791.

[7] Guex N, Peitsch MC (1997) Swiss Model and the swiss pdb viewer: An environment for comparative protein modelling. Electrophoresis. 18: 2714-23.

[8] Morris GM, Goodsell DS Automated docking using a Lamarckian Genetic and empirical binding free energy
[10] PDB Database: http://www.rcsb.org/ pdb/home/home.do.

[11] Pickup J, Williams G (1991) Textbook of Diabetes. Blackwell, London.

[12] Rohit KA, Ramya ST, Shravan KG (2011) 3D QSAR and docking studies of flavonoid derivatives on p56lck protein tyrosine kinase using PLS. Int. J Pharmacy Pharm Sci. 3(4): 44-52.

[13] Russo GL, Ciarcia G, Presidente E, Siciliano RA, Tosti E (2008) Cytotoxic and apoptogenic activity of a methanolic extract from the marine invertebrate Ciona intestinalis on malignant cell lines. Med. Chem. 4(2), 106-109.

[14] Satyavati GV, Neeraj T, Madhu S (1989) Indigenous Plant drugs for diabetes mellitus. Dia. Bulletea. 164Q- 90Q.

[15] Shuichi M (2002) Molecular modelling and structure based drug discovery studies of aldose reductase inhibitors. Chem Bio Informatics J. 2(3): 74-85.

[16] Steppan CM, Bailey ST, Bhat S (2001) The hormone resistin links obesity to diabetes. Nature. 409:307-12.

[17] Sundararajan S, Balajee R, Dhanarajan MS (2010) Comparitive docking analysis of neuraminidase with various inhibitors. Int.J Pharmacy Pharm Sci. 2(3): 83-5.

[18] Thompson, Mark A. "Argus lab 4.01" www.arguslab.com plknaria software LLc, Seattle, WA. 